\title{
The Relationship between Mental Health Components and Locus of Control in Youth
}

\author{
Mahnaz Shojaee1, Carmel French ${ }^{2}$ \\ Department of Child and Youth Studies, Mount Saint Vincent University, Halifax, Canada \\ Email: nazy.shojaee@hotmail.com
}

Received 24 March 2014; revised 21 April 2014; accepted 16 May 2014

Copyright (C) 2014 by authors and Scientific Research Publishing Inc. This work is licensed under the Creative Commons Attribution International License (CC BY). http://creativecommons.org/licenses/by/4.0/

\section{(c) (†) Open Access}

\begin{abstract}
Using Ryff's positive psychological theory as a conceptual framework, this research was focused on mental health or well-being to explore the degree to which mental health can be predicted by personality traits and demographic factors in Nova Scotian youth and young adults. This theory covered all critical features of well-being by taking benefits from different developmental, personality and clinical theories. Employing Ryff's inclusive theory that covered six dimensions including purpose in life, self-acceptance, positive relations with others, autonomy, environmental mastery, and personal growth, the researcher studied the relationship between mental health components and the locus of control. Participants: One hundred and seventy-two students of Mount Saint Vincent University were randomly selected and participated in this study. Measures: All participants completed three measures, Rotter's Locus of Control Scale, Ryff's Psychological Well-Being Scale and Demographic Questionnaire. Method: Quantitative methods such as bivariate correlation, ANOVA and hierarchical linear regression were used to explain the relationships between variables based on the research hypotheses. Results: The statistical analysis of data revealed that there was a positive and linear association between the internal locus of control and all six well-being components. Findings from the current research demonstrated that individuals who have an internal tendency in their locus of control are in higher levels of mental health in compression with individuals with external locus of control. Using hierarchical linear regression revealed that locus of control, gender, citizenship status, marital status can predict $41 \%$ of the variance in participants' mental health.
\end{abstract}

\section{Keywords}

Mental Health, Locus of Control, Autonomy, Self-Acceptance, Personal Growth, Purpose in Life, Environmental Mastery, Positive Relations with Others 


\section{Introduction}

Child and youth mental health issues are one of the controversial issues that has been central to many interdisciplinary studies (Kazdin, 2006; MacKean, 2011; Burns, Durkin, \& Nicholas, 2009; Santrock, MacKenzie-Rivers, Leung, \& Malcomson, 2005). It was estimated that in United States of America 20\% of all children (15 million) meet the diagnostic criteria for at least one mental health difficulty (Kazdin, 2006). Not only children, but also adolescents and young adults between 15 and 34 years of age are more at risk of having mental health difficulties. In fact, Burns et al. (2009) reported that $60 \%$ of adolescents' and young adults' disability caused by mental illnesses. Health Canada reported that $20 \%$ of Canadians will personally experience a mental illness during their lifetime. Of this proportion, persons aged 15 to 24 years old in Canada are at risk of experiencing mental health difficulties, as "over $10 \%$ of young adults [who had mental health difficulties] were hospitalized due to one of seven mental illnesses (e.g., anxiety disorders, bipolar disorders, schizophrenia, major depression, personality disorders, eating disorders, and attempted suicide) in general hospitals” (Health Canada Report, 2002: p. 19). Similarly a study of six Ontario post-secondary institutions found that approximately $4 \%$ of the students had a psychiatric condition, $15 \%$ had been treated by a professional for one or more mental health problems and 53\% indicated that they felt overwhelmed by anxiety (MacKean, 2011). These statistics reveal that mental health issues, including understanding its components, influential and associated factors, consequences, and interventions strategies, should be central to psycho-social studies.

Mental health is often viewed or described based on different theoretical or intervention approaches that they focus on various aspect of mental health. For example, in the medical approach, mental health is characterized by lack of symptoms or signs of disorders. This view of mental health is a psychopathological view in which abnormality is defined on the basis of pathological symptoms (Westerhof \& Keyes, 2010). From a biomedical sciences approach in which the concepts of disease and health are interconnected, a lack of specific symptoms may be considered a sign of mental health in people. This view does not increase our understanding of mental health. Murphy (2009) stated:

If disease is biological malfunction or abnormality, it follows that a healthy person is someone whose biological systems are all in order. But another way of looking at health insists that it is not just the absence of disease but the presence of something more; a positive state (p. 2).

Mental health then can be characterized by its components that determine an individual's positive state. Furthermore, the concepts of well-being, mental health and happiness are often used synonymously in this approach. Ryff (1989a, 1989b) also recognized the role of happiness in mental health. Ryff's theory (Ryff, 1989a, 1989b; Ryff \& Singer, 2008), in which hedonism and positive psychological views are predominant, characterizes mental health by its six major components: personal growth, self-acceptance, purpose in life, autonomy, positive relation with others, and environmental mastery. Corsini (1999) also noted that an individual's degree of positive selfesteem, happiness, and life-satisfaction can determine one's mental health. Mental health from these perspectives is defined as a "subjective evaluation of individual functioning" (Westerhof et al., 2010: p. 111). The World Health Organization (WHO, 2005, cited in Michaud \& Fombonne, 2005), likewise, defined mental health as a "state of well-being whereby individuals recognize their abilities, are able to cope with the normal stresses of life, work productively and fruitfully, and make a contribution to their communities” (p. 835). In WHO's definition of mental health, there are three major components (e.g., well-being, effective individual functioning and efficient functioning within a community-Westerhof \& Keyes, 2010) that reveal a positive view of mental health.

This positive view of mental health allows experts to determine the role of other behavioral and developmental domains such as personality traits in exploring mental health components. For example, Carver and ConnorSmith (2010) stressed that mental health should be considered in relation to other behavioral and developmental domains in which personality is linked. Since personality traits and coping (e.g., with stress, illnesses or other difficulties) are associated with each other, individuals with specific behavioral characteristics or personality traits should show positive mental health (Corr \& Matthews, 2009). For example, in Big Five theory of personality, which is introduced by Costa and MacCrae $(1980,1984)$, agreeableness (as a big trait of personality) can span social behavior and positive affect that both determine positive mental health (Canli, 2009). In Big Five theory of personality, most personality traits are relevant to different domains such as "physical and mental health, quality of social relationships, occupational choice, satisfaction and performance, and pro- and antisocial behaviors in the community” (Ozer \& Benet-Martinez, 2006 cited in Corr \& Matthews, 2009: p. xxxvii).

The relationship between mental health and behavioral traits are discussed not only in Big Five theory of per- 
sonality, but also in other theories. It was noted that individuals' personality characteristics can determine the level of their mental health (Corr \& Matthews, 2009; Carver \& Connor-Smith, 2010; Pervin, 1993). Among different personality theories, Rotter's theory is a unique perspective in which individuals develop within social-learning processes through which they constructing the main traits of their personalities including internal and/or external locus of control (Rotter, 1960 cited in Pufal-Struzik, 1998). In different scholarly studies, it has been found that there is a close relationship between the level of mental health in individuals and their behavioral orientations based on locus of control (Karayurt \& Dicle, 2008; Armstrong \& Boothroyd, 2008). Individuals whose locus of control is more internal have higher level of mental health (Karayurt \& Dicle, 2008; Adolfsson, Andersson, Elofsson, Rössner, \& Undén, 2005).

Although the relationships between different levels of personality orientation (based on Rotter's view) and mental health or mental illnesses were studied (Karayurt \& Dicle, 2008; Armstrong \& Boothroyd, 2008; Adolfsson et al., 2005), there are minimal studies about the relationships between locus of control and mental health components based on Ryff's view as a positive psychological approach. Therefore the purpose of this research is to study the association between internal/external locus of control and six components of mental health, identified by Ryff, in adolescents and young adults. In addition, this study will focus on demographic characteristics of young adults and their roles in predicting personality traits and mental health components. It is assumed that the result of this study can be used in different areas of child and youth studies including mental health intervention programs, early intervention programs to construct positive personality traits, public health care, and producing other theoretical and practical studies.

\section{A) Mental Health and Its Components}

From a medical perspective, mental health has been characterized by terms antonymous with disease, mental illnesses, and pathological symptoms/signs (Murphy, 2009). A healthy person was recognized as an individual whose physical functions were considered as major criteria in diagnosing diseases. Indeed, the World Health Organization (WHO), noted that the medical model views physical and mental health in terms of "objectivism" in which human physiology is considered as the criterion for being healthy (Murphy, 2009). WHO (1948, cited in Murphy, 2009) defined health as "a state of complete physical, mental and social well-being, and not merely the absence of disease or infirmity" (p. 2). However, focusing on mental health as "a state of well-being in which the individual realizes his or her own abilities, can cope with the normal stresses of life, can work productively and fruitfully, and is able to make a contribution to his or her community" (World Health Organization, 2005; cited in Westerhof \& Keyes, 2010: p. 111), demonstrates that this definition is also influenced by the objective or medical view (Westerhof \& Keyes, 2010; Murphy, 2009). What is absence in the medical perspective are the psychological components of mental health.

Using positive psychological perspectives, Ryff (Ryff, 1989a, 1989b; Ryff \& Singer, 2008) demonstrated that mental health (well-being) can be characterized by its six major components that cover different psycho-social aspects of human being. Thus, Ryff's view of well-being considers elements of hedonic and eudaimonic approaches in addition to major points of grounded personality theories such as those proposed by Allport, Rogers, Maslow, Erikson, Jung and others (see Figure 1, Ryff \& Marshall, 1999). Major components identified by Ryff include purpose in life, self-acceptance, positive relations with others, autonomy, environmental mastery, and personal growth (Ryff, 1989a, 1989b; Ryff \& Singer, 2008).

Scholarly studies revealed that these components have been extracted from different developmental, clinical and particularly personality theories (Ryff, 1989a, 1989b; Ryff \& Singer, 2008; Westerhof \& Keyes, 2010; McDowell, 2010). These theories were mentioned originally in first attempts of generating Ryff's model of well-being (Ryff \& Marshall, 1999). Similar to Ryff's stress on this originality, other studies showed that there is a close relationship between personality traits and mental health (Carver \& Connor-Smith, 2010; Corr \& Matthews, 2009). This association is prominent in some major components of mental health such as what was noted in relation to autonomy, or personal growth (Ryff \& Singer, 2008).

Referring to Rotter's theory of personality, it is noted that locus of control is not only associated with mental health, but it also determines the level of well-being function (Karayurt \& Dicle, 2008; Armstrong et al., 2008; Adolfsson et al., 2005). Since it is assumed that mental health components (e.g., autonomy, personal growth, environmental mastery and others) have relationships with personality traits, particularly with locus of control in Rotter's perspective, their roles are central to this study.

\section{B) Locus of Control in Rotter's Perspective}

Rotter's locus (Rotter, 1954, 1966, 1987, cited in Pervin, 1993) of control view is a part of his social learning 


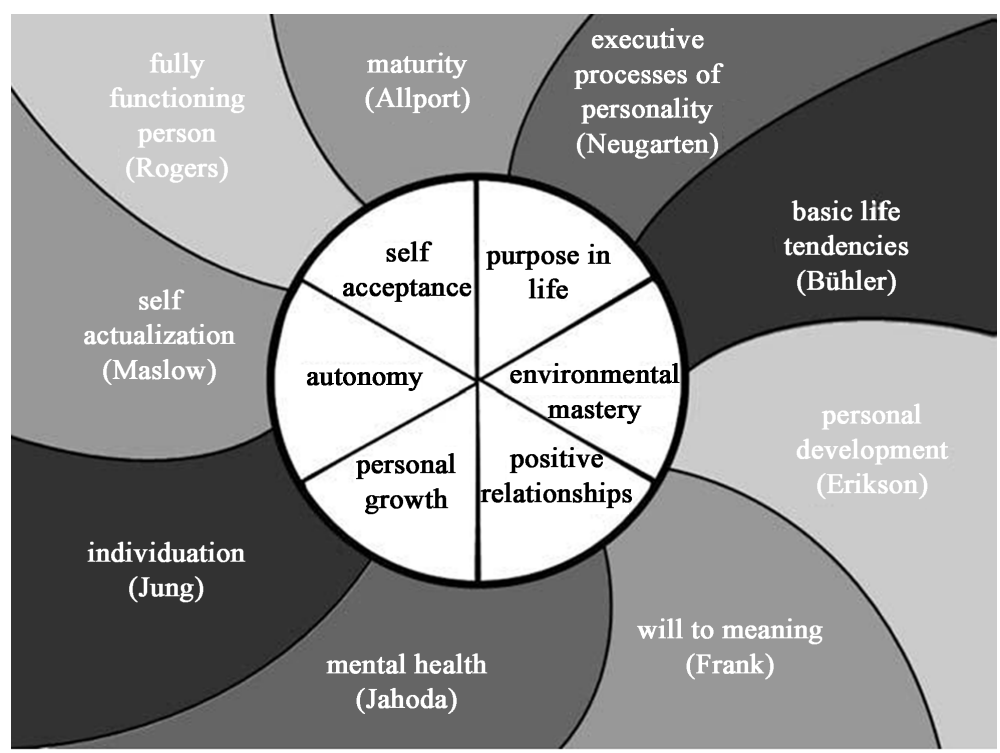

Figure 1. Core dimensions of well-being and their theoretical origins (ryff \& marshall, 1999).

theory of personality. This theory was originated from the integration of two major approaches in American psychology: the stimulus-response (S-R) theory and the cognitive or field position related to Lewin's theory (Graham \& Weiner, 1996). By integrating these theories, Rotter (Rotter, 1966, cited in Pervin, 1993) explained that human motivational behavior is a function of expectancy $(\mathrm{E})$ and reinforcement value (RV).

$$
\text { Behavior }=f(\mathrm{E}, \mathrm{RV})
$$

Rotter (Rotter, 1954 cited in Graham \& Weiner, 1996) stated that RV is related to the degree of preference for any reinforcement that is relative, and $\mathrm{E}$ is related to individuals' expectancies for success which is determined by people's past history of successful or unsuccessful experiences. Exploring the influences of $\mathrm{E}$ in human behavior, Rotter (Rotter, 1966, cited in Graham \& Weiner, 1996) found that expectancies of success are either skill-related situations or chance-related contexts. Studying more details of these situations, Rotter (Rotter, 1966; cited in Graham \& Weiner, 1996) realized that people manifest two broad yet different perceptions of situations and of their success that reflected either internal or external control. Later, Rotter postulated that individuals' personality is determined by having either internal locus of control or external locus of control (Pervin, 1993; Graham \& Weiner, 1996; Corr \& Matthews, 2009). Both types of personality traits, internal or external locus of control, create different motivational behaviors, tendencies, and cognitions.

Locus of control is defined as a person's tendency to see events as being controlled internally or externally (Rotter, 1966; cited in Lloyd \& Hastinhs, 2009). This tendency characterizes a person's perspective about self-independence and control by others (Corsini, 1999). Moreover, locus of control can determine behavior potential. Behavior potential (the likelihood of engaging in a particular behavior) is defined as a "function of expectancy (the probability that a given behavior will lead to a particular outcome) and reinforcements such as the outcomes of our behavior" (Lefcourt, 1976; cited in April, Dharani, \& Peters, 2012: p. 125). Since locus of control refers to the individuals' belief about controllability over what happens to them in life, it is defined as a personality trait or construct that reveals how individuals perceive their ability to control life events or environment (April et al., 2012). This belief can be characterized on one continuum on which two extremes can be recognized: internal locus of control and external locus of control (see Figure 2).

Based on this theory (locus of control theory), people who would believe that an outcome is dependent on their own behavior, and feel individually responsible for the events happen to them have internal locus of control (Lloyd \& Hastings, 2009; Pannells \& Claxton, 2008). This type of people is characterized as "internalisers" (Bozorgi, 2009: p. 3). In contrast, people with external locus of control would believe that outcomes are not as a result of their own actions and are the consequences of fate, luck, chance and environmental influences (Lloyd \& Hastings, 2009; Pannells \& Claxton, 2008). Such people are recognized as “externalisers” (Bozorgi, 2009: p. 3).

Unlikely to multi-traits personality theories, particularly Allport's and Cattell’s theories (Pervin, 1993), locus 

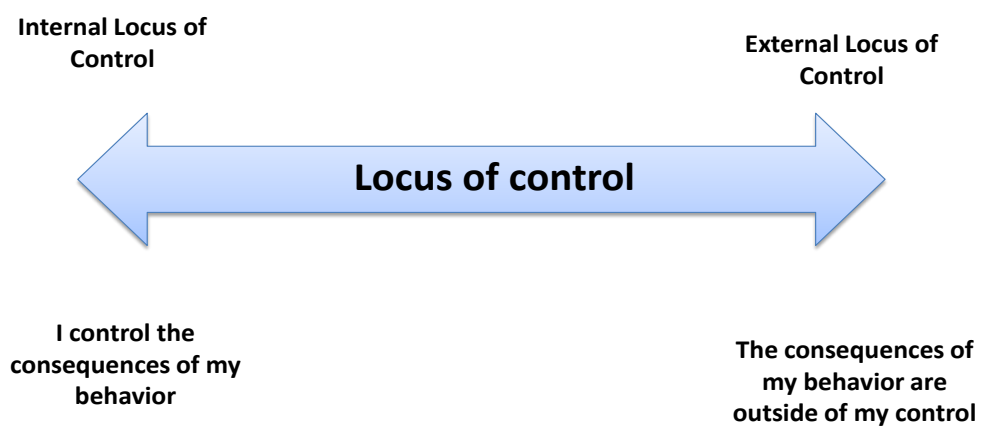

Figure 2. The continuum of locus of control.

of control of control in Rotter's single-trait theory is situation specific (Rotter, 1975 cited in Lloyd \& Hastings, 2009). Rotter (1975) demonstrated that locus of control is not typology or predisposition, but it is a general belief or expectancy and situation-based trait. Thus, an individual's locus of control can vary across situations depending two main factors: past history of success and reinforcement and his or her expectancies (Graham \& Weiner, 1996; Lloyd \& Hastings, 2009). Based on this specific characteristic of locus of control, it has been found that individuals who faced rich meaningful experiences changed their causal attribution orientations (Lefcourt, 1976 cited in Bozorgi, 2009). Karayurt and Dicle (2008) demonstrated that when students progress in their educational programs their locus of control shift to internal. They have indicated that when students are faced problem-based learning program their internal locus of control will increase (Karayurt \& Dicle, 2008). Based on similar finding (Sandler \& Lakey, 1982 cited in Bozorgi, 2009) it is supposed that stress-challenge environment and controlled risk-taking education (e.g., outdoor-adventure programs) can influence people's locus of control. Not only involving in social experiences can shift individuals' locus of control from external to internal, but also from McArthur's (1999) finding can be deduced that changing socioeconomic status can affect individuals' locus of control. These finding are congruent with social learning theory in which locus of control is situation based, that is, having more social experiences can change locus of control (Rotter, 1975).

\section{C) Mental Health and Locus of Control}

A review of literature on locus of control reveals that this personality trait has close association with different physical and mental illnesses as well as positive mental health features (Arslan et al., 2009; Coyne et al., 2011; Field \& Kruger, 2008; Nabors et al., 2010). A wide range of physical diseases has been studied in relation to locus of control in which chronic pain was central (Baker et al., 2008).

Apart from physical illnesses, the association between mental illnesses and locus of control was central to many scholarly studies (Lloyd \& Hastings, 2009; Field \& Kruger, 2008; Karayurt \& Dicle, 2008). A belief with which person has enough ability to achieve desired outcome when he or she becomes ill mentally or physically is called internal health locus of control (Shelley \& Pakenham, 2004). This belief is a major determinant in people's reaction to mental and physical illnesses. Comparing with external locus of control, it has been found that in both physical and mental illnesses having internal locus of control is a positive predictors in coping with diseases (Shelley \& Pakenham, 2004; Lloyd et al., 2009; Field \& Kruger, 2008). For example, Marks, (1998 cited in April et al., 2012) reported that "locus of control in cultures that fostered a high perception of external control also fostered higher rates of suicide" (p. 124). April et al. (2012) argued that with external locus of control, individuals are more vulnerable to depression and they are weak in responsiveness to anti-depressive medications. Those individuals have also lower levels of happiness (April et al., 2012). Focusing on depression, it has been argued that helplessness and hopelessness are its major symptoms (DSM IV-TR, 2000). Since hopelessness is directly related to the beliefs by which individuals feel unable to control the circumstances and the consequences of their conditions; it is assumed that people with external locus of control suffer from hopelessness and consequently they are vulnerable to become depressed (Field \& Kruger, 2008). Also, Coyne and Thompson (2011) demonstrated that there is an association between maternal depressive symptoms (e.g., hopelessness), parental locus of control, and children internalizing problems.

It is also noted that persons with internal locus of control had high level of grade points and felt self-confident in predicting their success for academic performance (Rose, Hall, Bolen, \& Webster, 1996 cited in Bozorgi, 2009). In addition to self-confidence and problem-solving skills, Phares (1968, cited in Bozorgi, 2009) studied self-pity and coping with situations in relation with locus of control resulted that people with external locus of 
control are being self-pity and are unable to cope with the reality of situation. Coping with reality of situation indicates personal adjustment that is a factor by which individuals can adapt themselves with life stresses and with any changes that cause distress or difficulties. This behavioral feature is also one of the major components of mental health noted in different definitions of mental health (e.g., WHO's, 2005 cited in Westerhof \& Keyes, 2010). Personal adjustment is associated with self-perception that it is rooted in personality trait of locus of control and determining how individuals interpret the cause-and-effect relationship between their behaviors and their outcomes (Pufal-Struzik, 1999). In contrast to people with external locus of control, individuals who interpret the outcomes of their behaviors based on luck, destiny, and control of others (persons with external locus of control) are not well-adjusted and do not react constructively to frustrating situations (Pufal-Struzik, 1999; Bozorgi, 2009).

In this regard, the important point is inter-correlation among positive self-perception, having good relation with others, personal adjustment and locus of control. Considering different literature, it is revealed that they have a direct, positive and linear association with the internal locus of control that indicates good mental health status (Pufal-Struzik, 1999; Leotti, Iyengar, \& Ochsner, 2010; Lloyd \& Hastings, 2009). Considering different reasons, one reason of a higher level of mental health in such people is that people with a sense of personal control over events can restrain their physical reactions to stress such as automatic arousal and stress hormone release (Leotti et al., 2010). This type of personal control (self-control) is assumed to increase the level of human's immune system as well as mental health (Leotti et al., 2010). As a sense of personal control is rooted in locus of control, it helps college students to increase their mental health status (Karayurt \& Dicle, 2008). Likewise, Pannells and Claxton (2008) examined 171 university students and found that students with the internal locus of control had a higher level of mental health manifesting with happiness, academic achievement and creativity in which happiness had a higher correlation with the internal locus of control.

The role of locus of control in individuals' positive psychological characteristics has been studied separately (Pannells \& Claxton, 2008; Pufal-Struzik, 1998; Graffeo \& Silvestri, 2006; Haybron, 2011; Crisp, 2008). Although these noted characteristics may be representatives of components of mental health; the components of mental health in Ryff's theory (Ryff, 1989a; Ryff, \& Singer, 2006) are the main characteristics of mental health that were extracted from different developments, personalities and clinical theories. Even though these components were studied in numerous studies indicating the accuracy of this perspective about mental health (Abbott, Ploubidis, Huppert, Kuh, \& Croudace, 2010; Baker, Soto, Perez, \& Lee, 2012; Bishop, 2006), the role of locus of control in all components of mental health has not been studied in one comprehensive investigation. Focusing on Ryff's components of mental health including personal growth, self-acceptance, purpose in life, autonomy, positive relations with others, and environmental mastery, the role of locus of control in these components is central to this study. Therefore, the purpose of current study includes: determining the role of the locus of control as a personality trait in all components of mental health based on Ryff's theory (psychological well-being theory). It was hypothesised that individuals who score high on measures of the internal locus of control will also score high on Ryff's measure of mental health for all six components (purpose in life, personal growth, environmental mastery, autonomy, self acceptance, positive relationship with others).

\section{Method}

\subsection{Participants}

One hundred and seventy-two students, between the ages of 19 and 30 years old, enrolled at MSVU in either an art, science or professional degree program participated in this study. Categorizing the age range in 3 groups, the first group was between 19 and 21 years old with the frequency of 43 (25\% percent of the whole participants). The second group was between 22 and 26 years old with the frequency of 96 people (56\%). The last group was aged from 27 to 30 years old with the frequency of 31 people (18\%). Of these groups, two participants did not indicate their ages. Regarding the gender, likewise the original population of the MSVU, 99 participants were female with $58 \%$, and 71 were male with $41 \%$.

\subsection{Measures}

In this study, mental health and its components was measured by Ryff's Psychological Well-Being scale (PWB, 42 items) (Ryff, 1989a, 1989b; Ryff \& Singer, 2008; Ryff \& Singer, 2006; Ryff \& Keyes, 1995). Ryff (1989a) developed a model of psychological well-being, or positive mental health (Cheng \& Chan, 2005) based on clin- 
ical theories, life-span developmental and personality theories (Van Dierendonck, 2005). Ryff's approach represents an optimistic outlook on life, stressing development and personal growth. The scale covers six psychological aspects of mental health, including self-acceptance, positive relations with others, autonomy, environmental mastery, purpose in life, and personal growth.

Furthermore, the researcher used the Rotter's scale (Rotter, 1954, 1966, 1987 cited in Pervin, 1993) including 29 items to measure locus of control. Rotter's $(1954,1966)$ scale measures two different types of locus of control, internal and external. The higher score indicates that the individual more likely possess internal locus of control, and the lower score shows that the individual possess external locus of control (Pannells \& Claxton, 2008).

\subsection{Procedures}

In this process, the researcher used systematic multistage random sampling. Limited to one statistical society such as university (e.g. Mount Saint Vincent University), systematic multistage random sampling is an appropriate sampling design. In this sampling plan the following stages were used: 1) determining and providing the frame of sampling like programs, 2) selecting randomly some programs (e.g. Psychology and Business Administration), 3) identifying a list of all on campus classes in selected programs, 4) selecting some (five to seven) classes from stage 3 randomly, 5) going to the selected classes based on stage 4 with the instructors' permission, 6) using random number or other ways (simple random ways) to choose students based on age variable, 7) elaborating the goals of study, also accentuating the ethics and confidentiality of responses and explain the ethical issues of the questionnaires (in which there is no need to write any ID information), 8) administrating the scales and questionnaires on the selected students in stage 6 and 7, and 9) preparing data for next step (statistical analysis).

\subsection{Data Analysis}

The researcher used descriptive analysis including mean, standard deviation, variation and others to summarize the characteristics of all participants. The descriptive analysis provided bases to examine the relationships between variables in research hypotheses (Cohen, 1996). Since statistical scales of those questionnaires are interval or at least categorical scale, the researcher used parametric statistics to analyze data along with nonparametric statistics for categorical or nominal variables (e.g., demographic variables). In this step the following statistical methods were used.

1) Linear Regression Analysis.

2) Bivariate Correlation, T-Tests and ANOVA.

However, the researcher ensured that the samples and data have met the statistical assumptions of the noted methods.

\section{Results}

It was assumed that individuals who score high on measures of internal locus of control will also score high on Ryff's measure of mental health for all six components (purpose in life, personal growth, environmental mastery, autonomy, self acceptance, positive relationship with others). To test this hypothesis, bivariate correlation was used and its results were shown in Table 1.

As Table 1 shows, Rotter-internal LOC have positive correlations with all components of Ryff's PWB scale, and all correlations are significant $(p<.01)$. Purpose in life as a component of mental health has the highest correlation with Rotter-Internal LOC with $\mathrm{r}=.34, p<.000$. In contrast, the component of personal growth has low association with Rotter-Internal LOC with $\mathrm{r}=.20, p<.05$.

Regarding to the Rotter-External LOC and its relation with mental health, all of the components of Ryff's PWB scales have negative significant correlation. Overall it can be said that individual who had high score in Rotter-internal (had internal LOC), had high score in components of Ryff's PWB scale too. Also, participants whose score was high in Rotter-External had low score in components of Ryff's PWB scale. This finding indicates that mental health components are associated with internal LOC. Therefore, the hypothesis, by which mental health components were assumed to be correlated with Rotter's Internal LOC, was accepted.

In addition, the correlation between total score of Rotter LOC and total score of the Ryff's PWB Scale was calculated. As it is demonstrated in Table 2, there is a positive association between these two scales $r=.312(p$ $<.01)$. 
Table 1. Bivariate correlations between rotter LOC and components of Ryff's PWB Scale.

\begin{tabular}{ccccccccc}
\hline & & $\begin{array}{c}\text { Rotter- } \\
\text { internal LOC }\end{array}$ & Autonomy & $\begin{array}{c}\text { Positive } \\
\text { relation with } \\
\text { others }\end{array}$ & $\begin{array}{c}\text { Environmental } \\
\text { mastery }\end{array}$ & $\begin{array}{c}\text { Personal } \\
\text { growth }\end{array}$ & $\begin{array}{c}\text { Purpose in } \\
\text { life }\end{array}$ & Self-acceptance \\
\hline $\begin{array}{c}\text { Rotter- } \\
\text { internal LOC }\end{array}$ & Pearson r & 1 & $.21^{* *}$ & $.23^{* *}$ & $.28^{* *}$ & $.20^{*}$ & $.34^{* * *}$ & $.28^{* *}$ \\
& Sig (2-tailed) & .00 & .008 & .004 & .001 & .012 & .000 & .001 \\
$\begin{array}{c}\text { Rotter- } \\
\text { external } \\
\text { LOC }\end{array}$ & Pearson r & $-.99^{* *}$ & $-.21^{* *}$ & $-.24^{* *}$ & $-.26^{* *}$ & $-.20^{*}$ & $-.34^{* *}$ & $-.28^{* *}$ \\
& Sig (2-tailed) & .000 & .009 & .003 & .001 & .013 & .000 & .000 \\
\hline
\end{tabular}

"Correlations are significant at the $p<.05 .{ }^{* *}$ Correlations are significant at the $p<.01$.

Table 2. The relationship between Rotter LOC and Ryff's PWB.

\begin{tabular}{cccc}
\hline & & Rotter-internal LOC & Ryff's total PWB \\
\hline \multirow{2}{*}{ Rotter LOC } & Pearson correlation & 1 & $.312^{* *}$ \\
& Sig. (2-tailed) & & .000 \\
Ryff's total PWB & $\mathrm{N}$ & 163 & 148 \\
& Pearson correlation & $.312^{* *}$ & .000 \\
\hline
\end{tabular}

${ }^{* *}$ Correlation is significant at the .01 level (2-tailed).

\section{General Predictive Equation}

With regard to the positive correlation between locus of control and mental health $(\mathrm{r}=.312, p<.000)$, and the range of scores in Rotter LOC Scale (from 5 to 23, see Table 3), it is possible to use the predictive regression equation $\hat{Y}=\mathrm{a}+(\mathrm{b} 1 \times \mathrm{X} 1)$ for the model 1 to predict participants' scores on mental health (Ryff's well-being scale). For example, if somebody has a score of 23 (Maximum score) on the Rotter LOC Scale, his or her score on Ryff's Well-Being Scale will be Ý $=164.225+(2.130 \times 23)=213.215$. For a moderate score on Rotter LOC Scale, such as 13, the result will be Ý $=164.225+(2.130 \times 13)=191.915$ on Ryff's Scale. For a person with high tendency of external locus of control with a score such as 5, the score on Ryff's Well-Being Scale will be Ý $=164.225+(2.130 \times 5)=174.875$. Using these scores, it is possible to draw the regression line of prediction (Figure 3).

\section{Discussion}

Reviewing the related literature reviews indicated that most studies have been focused on the role of locus of control in predicting mental illnesses or physical diseases, and there are few studies concentrated on the role of locus of control in the positive features or the comprehensive psychological components of mental health. Thus, the relationship between locus of control and the positive components of mental health in Ryff's theory (Ryff, 1989a, 1989b) (e.g., autonomy, purpose in life, environmental mastery, personal growth, positive relationship with others, and self-acceptance) was central to this study. The purpose of this study was ascertaining the role of locus of control as a personality trait in all components of mental health based on Ryff's theory (Ryff, 1989a) (psychological well-being theory). Using Ryff's theory (Ryff, 1989a, 1989b) of positive psychological well-being (mental health) and a quantitative approach, the current study kept distance from the medical (symptomatic) model and focused on the predictive effects of locus of control on mental health components as measured by Ryff's Psychological Well-Being Scale (PWB) (Ryff, 1989a). The international and Canadian students of Mount Saint Vincent University in Halifax, Nova Scotia were targeted population of the researcher's 


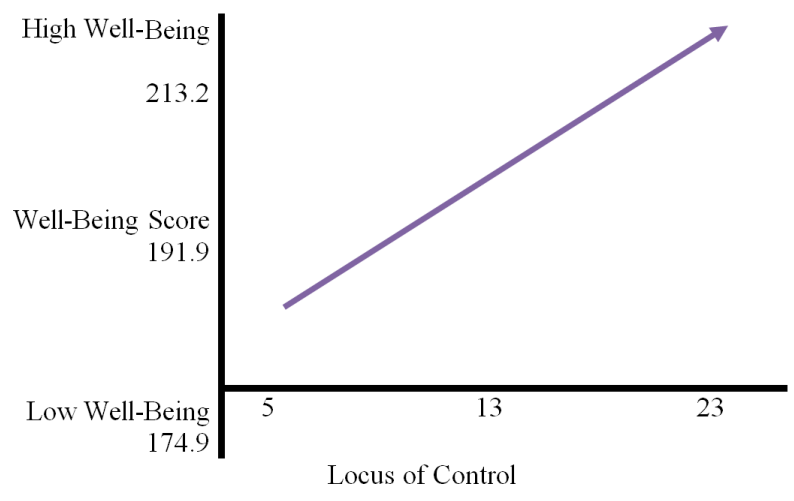

Figure 3. Regression line of well-being via locus of control score.

Table 3. Descriptive statistics of scales.

\begin{tabular}{ccccccc}
\hline & N & Range & Minimum & Maximum & Mean & Std. deviation \\
\hline Total score of Rotter LOC scale & 163 & 18 & 5 & 23 & 12.92 & 3.925 \\
Total score of Ryff's & 154 & 140 & 110 & 250 & 190.45 & 28.307 \\
PWB scale 42 items & 148 & & & & & \\
Valid N (listwise) & 140 & & & & \\
\hline
\end{tabular}

sample study ( $\mathrm{N}=172$ ). The participants completed two measures, Ryff's Psychological Well-Being Scale (42 items), Rotter's LOC (29 items) in order to measure their tendency about locus of control. Data from 172 student participants on completed measures was analyzed to examine the hypothesis.

Based on the hypothesis, the researcher used bivariate correlation to examine the associations between locus of control and the components of mental health. The results showed that there are positive significant associations between six components of mental health and locus of control (see Table 1). This finding rejects null hypothesis and supports the hypothesis by which the association between locus of control and each well-being component were assumed to be directed and positive. This association means that individuals with internal locus of control have higher level of mental health.

In this regards, one of the components of Ryff's psychological well-being scale is purpose in life. As mentioned above, mature individuals are characterized by having life's purpose, having intentionality, and directedness, it is assumed that people's well-being is identified by this component (Ryff \& Singer, 2008). Particularly, if someone enjoys making plans for his or her future and works for making them a reality; or being an active person in carrying out his or her plans, he/she has a purpose in life (Ryff \& Singer, 2008). In contrast, as people with external locus of control would believe that outcomes are not as a result of their own actions and are the consequences of fate, luck, chance and environmental influences (Lloyd \& Hastings, 2009; Pannells \& Claxton, 2008), and they usually do not plan for future; thus they do not have clear purpose in life. Therefore, the results from the current study aligned with those of previous studies and indicated that purpose in life had significant positive relation with locus of control.

Self-acceptance is another component of mental health which was previously defined as a sense of recognition of personal abilities and achievements as well as acknowledging and accepting personal limitations (Ryff, 1989a). Findings from the current study also demonstrated that internal locus of control is positively associated with self-acceptance. This finding has also convergence with Pufal-Struzik's (1999) research, in which personal adjustment is associated with self-perception. Since personal adjustment is rooted in personality trait of locus of control, and determines how individuals interpret the cause-and-effect relationship between their behaviors and their outcomes; it is deduced that self-acceptance is affected by personality trait of locus of control.

The other component of Ryff's theory of mental health, which has positive significant association with locus of control, is environmental mastery. This component indicates people's talent in selecting or making the environment around them suitable to their personal-psychological situation (Ryff \& Keyes, 1995). Relating this component to locus of control, Karayurt and Dicle (2008) revealed that persons with external locus of control were less self-confident and had poorer skills in problem-solving. It is assumed that if people would like to have 
a suitable environment for themselves, need to solve the facing problems and to make personal and psychological atmosphere positive and appropriate. Therefore, it is assumed that environmental mastery has strong association with internal locus of control. This assumption was supported by the findings of the present study.

Autonomy is the other component of Ryff's Psychological Well-Being Scale that had correlation with locus of control positively in this study. Autonomy can be characterized by self-determination, independence, and the regulation of behavior from within (Ryff, 1989a; Ryff \& Singer, 2008). Based on Ryff's view (Ryff, 1989a, 2008), this component of mental health has close association with major characteristics of self-actualizers in personality theories such as having an "internal locus of evaluation", "showing autonomous functioning" and "resistance to enculturation" (p. 21). On the other hand, it was discussed that internal locus of control has close association with both self-regulation and autonomy (Monshi Toussi \& Ghanizadeh, 2012), that it was corroborated by the present study.

Positive relationship with others is one of the major components of mental health, which is characterized by having warm and trusting interpersonal relationships, and also being able to love other people or having strong feeling of empathy (Ryff \& Singer, 2008). Many researchers stated that this component has direct, positive and linear association with internal locus of control (Pufal-Struzik, 1999; Leotti, Iyengar, \& Ochsner, 2010; Lloyd \& Hastings, 2009). Findings from present study support this opinion that people with internal locus of control has more intimacy and a close affiliation with others.

The other component of Ryff's theory (Ryff, 1989a) is personal growth that pertains to an individual's potential to develop positive characteristics (Ryff \& Singer, 2008). Positive and significant association between personal growth and internal locus of control revealed that people with internal locus of control has a tendency to develop their personal abilities and to actualize their potentialities in a positive ways. This finding of the current study aligns with the Robitschek's (1998) and Pufal-Struzik's (1998) studies. This link is not only in efforts in academic and social conditions, but also individuals with internal locus of control indicated that they are successful in health-related behaviors too, such as to stop smoking and looking health-related knowledge.

\section{Conclusion}

In conclusion, Ryff's Psychological Well-Being Scale as a total score and each of the all six components had a direct, significant and positive association with Rotter's Locus of Control Scale in the randomly sample of the young adult population of the Mount Saint Vincent University in Halifax, Canada. In order to lighten the future research path way, based on the findings and limitations in the present study, the following suggestions can be offered. First, since in Rotter's (1975) theory, the locus of control is situation-based, and the situation is directly related to the different environments and cultures. The researcher recommends a cross-cultural study for future studies, in which similarities and differences of the cultures in terms of the locus of control can be examined. Second, the research sample in this study was university students. It would be meaningful to scrutinize a general segment of the population to assess their tendency of the locus of control and whether it influences their life style and life choices. Also, future studies could look at the effect of growing up in an urban versus a rural environment on perceptions of the locus of control.

\section{References}

Abbott, R., Ploubidis, G., Huppert, F., Kuh, D., \& Croudace, T. (2010). An Evaluation of the Precision of Measurement of Ryff's Psychological Well-Being Scales in a Population Sample. Social Indicators Research, 97, 357. http://dx.doi.org/10.1007/s11205-009-9506-x

Adolfsson, B., Andersson, I., Elofsson, S., Rössner, S., \& Undén, A. (2005). Locus of Control and Weight Reduction. Patient Education and Counseling, 56, 55. http://dx.doi.org/10.1016/j.pec.2003.12.005

April, A. K., Dharani, B., \& Peters, K. (2012). Impact of Locus of Control Expectancy on Level of Well-Being. Review of European Studies, 4. http://dx.doi.org/10.5539/res.v4n2p124

Armstrong, M. I., \& Boothroyd, R. A. (2008). Predictors of Emotional Well-Being in At-Risk Adolescent Girls: Developing Preventive Intervention Strategies. The Journal of Behavioral Health Services \& Research, 35, 435.

http://dx.doi.org/10.1007/s11414-006-9048-9

Arslan, C., Dilmaç, B., \& Hamarta, E. (2009). Coping with Stress and Trait Anxiety in Terms of Locus of Control: A Study with Turkish University Students. Social Behavior and Personality, 37, 791-800.

http://dx.doi.org/10.2224/sbp.2009.37.6.791 
Baker, A. M., Soto, J. A., Perez, C. R., \& Lee, E. A. (2012). Acculturative Status and Psychological Well-Being in an Asian American Sample. Asian American Journal of Psychology, 3, 275. http://dx.doi.org/10.1037/a0026842

Baker, A. T., Buchanan, T. N., \& Corson, N. (2008). Factors Influencing Chronic Pain Intensity in Older Black Women: Examining Depression, Locus of Control, and Physical Health. Journal of Women's Health, 17, 869-878. http://dx.doi.org/10.1089/jwh.2007.0452

Bishop, A. J. (2006). Age and Gender Differences in Adaptation and Subjective Well-Being of Older Adults Residing in Monastic Religious Communities. Pastoral Psychology, 55, 131-143. http://dx.doi.org/10.1007/s11089-006-0035-0

Bozorgi, S. (2009). On the Relationship between Locus of Control and the Grade Point Average of the Iranian Azad University EFL Students. Online Submission. http://files.eric.ed.gov/fulltext/ED505569.pdf

Burns, J. M., Durkin, L. A., \& Nicholas, J. (2009). Mental Health of Young People in the United States: What Role Can the Internet Play in Reducing Stigma and Promoting Help Seeking? Journal of Adolescent Health, 45, 95. http://dx.doi.org/10.1016/j.jadohealth.2008.12.006

Canli, T. (2009). Neuroimaging of Personality. In P. J. Corr, \& G. Matthews (Eds.), The Cambridge Handbook of Personality Psychology. Cambridge: Cambridge University Press. http://dx.doi.org/10.1017/CBO9780511596544.022

Carver, C. S., \& Connor-Smith, J. (2010). Personality and Coping. Annual Review of Psychology, 61, 679-704. http://dx.doi.org/10.1146/annurev.psych.093008.100352

Cheng, S., \& Chan, A. C. M. (2005). Measuring Psychological Well-Being in the Chinese. Personality \& Individual Differences, 38, 1307. http://dx.doi.org/10.1016/j.paid.2004.08.013

Cohen, B. (1996). Explaining Psychological Statistics. USA: Brooks/Cole Publishing.

Corr, P. J., \& Matthews, G. (2009). The Cambridge Handbook of Personality Psychology. Cambridge: Cambridge University Press. http://dx.doi.org/10.1017/CBO9780511596544

Corsini, J. R. (1999). The Dictionary of Psychology. Philadelphia, PA: Taylor \& Francis Press.

Costa, P. T., \& McCrae, R. R. (1980). Influence of Extraversion and Neuroticism on Subjective Well-Being: Happy and Unhappy People. Journal of Personality and Social Psychology, 38, 668-678. http://dx.doi.org/10.1037/0022-3514.38.4.668

Costa, P. T., \& McCrae, R. R. (1984). Personality as a Lifelong Determinant of Well-Being. In C. Malatesta, \& C. Izard (Eds.), Affective Process in Adult Development and Aging (pp. 141-157). Beverly Hill, CA: Sage.

Coyne, W. L., \& Thompson, D. A. (2011). Maternal Depression, Locus of Control, and Emotion Regulatory Strategy as Predictors of Preschoolers' Internalizing Problems. Journal of Child and Family Studies, 20, 873-883.

http://dx.doi.org/10.1007/s10826-011-9455-2

Crisp, R. (2001). Well-Being. In N. E. Zalta (Ed.), The Stanford Encyclopedia of Philosophy. http://plato.stanford.edu/archives/win2008/entries/well-being/

Field, W., \& Kruger, C. (2008). The Effect of an Art Psychotherapy Intervention on Levels of Depression and Health Locus of Control Orientations Experienced by Black Women Living with HIV. South African Journal of Psychology, 38, 467478. http://www.msvu.ca:2048/login?url http://search.ebscohost.com/login.aspx?direct=true\&db=aph\&AN=34993547\&site=ehost-live\&scope=site http://dx.doi.org/10.1177/008124630803800302

Graffeo, L. C., \& Silvestri, L. (2006). Relationship between Locus of Control and Health-Related Variables. Education, 126, 593-597.

Graham, S., \& Weiner, B. (1996). Theories and Principles of Motivation. In D. C. Berliner, \& R. Calfee (Eds.), Handbook of Educational Psychology (pp. 63-84). New York: Macmillan.

Haybron, D. (2011). Happiness. In N. E. Zalta (Ed.), The Stanford Encyclopedia of Philosophy. http://plato.stanford.edu/archives/fall2011/entries/happiness/

Health Canada (2002). A Report on Mental Illnesses in Canada. http://www.phac-aspc.gc.ca/publicat/miic-mmac/pdf/men_ill_e.pdf

Karayurt, Ö., \& Dicle, A. (2008). The Relationship between Locus of Control and Mental Health Status among Baccalaureate Nursing Students in Turkey. Social Behavior \& Personality: An International Journal, 36, 919-930.

http://www.sbpjournal.com/index.php/sbp/article/view/1772 http://dx.doi.org/10.2224/sbp.2008.36.7.919

Kazdin, A. E. (2006). Child-Rearing: Wish I Had Time for It, but I Have to Get to Work and You Have to Get to Your Lesson. A Review of the Parenting Crisis: Parenting Today’s Teenagers by Scott Wooding. PsycCritiques, 51. http://dx.doi.org/10.1037/a0002078

Keyes, C. L. M. (2007). Promoting and Protecting Mental Health as Flourishing: A Complementary Strategy for Improving National Mental Health. American Psychologist, 62, 95-108. http://dx.doi.org/10.1037/0003-066X.62.2.95 
Leotti, L. A., Iyengar, S. S., \& Ochsner, K. N. (2010). Born to Choose: The Origins and Value of the Need for Control. Trends in Cognitive Sciences, 14, 457-463. http://dx.doi.org/10.1016/j.tics.2010.08.001

Lloyd, T., \& Hastings, R. P. (2009). Parental Locus of Control and Psychological Well-Being in Mothers of Children with Intellectual Disability. Journal of Intellectual \& Developmental Disability, 34, 104-115. http://dx.doi.org/10.1080/13668250902862074

MacKean, G. (2011). Mental Health and Well-Being in Postsecondary Education Settings: A Literature and Environmental Scan to Support Planning and Action in Canada. CACUSS Pre-Conference Workshop: Student Mental Health: A Call to Action, Toronto.

Michaud, P. A., \& Fombonne, E. (2005). ABC of Adolescence Common Mental Health Problems. British Medical Journal, 330, 835-838. http://dx.doi.org/10.1136/bmj.330.7495.835

Monshi Toussi, M. T., \& Ghanizadeh, A. (2012). A Study of EFL Teachers’ Locus of Control and Self-Regulation and the Moderating Role of Self-Efficacy. Theory and Practice in Language Studies, 2, 2363-2371. http://dx.doi.org/10.4304/tpls.2.11.2363-2371

Murphy, D. (2009). Concepts of Disease and Health. In N. E. Zalta (Ed.), The Stanford Encyclopedia of Philosophy. http://plato.stanford.edu/archives/sum2009/entries/health-disease/

Nabors, L., McGrady, E. M., \& Kichler, J. (2010). Children’s Attitudes toward Their Diabetes, Locus of Control, and HbA1c Levels. Journal of Developmental and Physical Disabilities, 22, 475-484.

Pannells, T. C., \& Claxton, A. F. (2008). Happiness, Creative Ideation, and Locus of Control. Creativity Research Journal, 20, 67-71. http://dx.doi.org/10.1080/10400410701842029

Pervin, A. L. (1993). Personality: Theory and Research. Toronto: John Wiley \& Sons, Inc.

Pufal-Struzik, I. (1998). Self-Acceptance and Behaviour Control in Creatively Gifted Young People. High Ability Studies, 9, 197-205. http://www.tandfonline.com/doi/abs/10.1080/1359813980090205 http://dx.doi.org/10.1080/1359813980090205

Robitschek, C. (1998). Personal Growth Initiative: The Construct and Its Measure. Measurement and Evaluation in Counseling and Development, 30, 183-189.

Rotter, J. B. (1954). Social Learning and Clinical Psychology. New York: Prentice-Hall.

Rotter, J. B. (1966). Generalized Expectancies for Internal versus External Control of Reinforcement. Psychological Monographs, 80, 609. http://dx.doi.org/10.1037/h0092976

Rotter, J. B. (1975). Some Problems and Misconceptions Related to the Construct of Internal versus External Control of Reinforcement. Journal of Consulting and Clinical Psychology, 43, 56-67. http://dx.doi.org/10.1037/h0076301

Ryff, C. D. (1989a). Beyond Ponce de Leon and Life Satisfaction: New Directions in Quest of Successful Ageing. International Journal of Behavioral Development, 12, 35-55. http://jbd.sagepub.com/content/12/1/35.short http://jbd.sagepub.com/content/12/1/35.full.pdf+html http://dx.doi.org/10.1177/016502548901200102

Ryff, C. D. (1989b). Happiness Is Everything, or Is It? Explorations on the Meaning of Psychological Well-Being. Journal of Personality and Social Psychology, 57, 1069-1081. http://dx.doi.org/10.1037/0022-3514.57.6.1069

Ryff, C. D., \& Keyes, C. L. M. (1995). The Structure of Psychological Well-Being Revisited. Journal of Personality \& Social Psychology, 69, 719-727. http://psycnet.apa.org/journals/psp/69/4/719/ http://dx.doi.org/10.1037/0022-3514.69.4.719

Ryff, C. D., \& Marshall, W. V. (1999). The Self and Society in Aging Processes. New York: Spring Publishing Company, Inc.

Ryff, C. D., \& Singer, B. H. (2006). Best News Yet on the Six-Factor Model of Well-Being. Social Science Research, 35, 1103-1119. http://dx.doi.org/10.1016/j.ssresearch.2006.01.002

Ryff, C. D., \& Singer, B. H. (2008). Know Thyself and Become What You Are: A Eudaimonic Approach to Psychological Well-Being. Journal of Happiness Studies, 9, 13-39.

Santrock, W. J., MacKenzie-Rivers, A., Leung, H. K., \& Malcomson, T. (2005). Life-Span Development. McGraw-Hill Ryerson.

Shelley, M., \& Pakenham, K. (2004). External Health Locus of Control and General Self-Efficacy: Moderators of Emotional Distress among University Students. Australian Journal of Psychology, 56, 191-199.

http://dx.doi.org/10.1080/00049530412331283336

Van Dierendonck, D. (2005). The Construct Validity of Ryff's Scales of Psychological Well-Being and Its Extension with Spiritual Well-Being. Personality \& Individual Differences, 36, 629-643.

http://dx.doi.org/10.1016/S0191-8869(03)00122-3 
Westerhof, G., \& Keyes, C. (2010). Mental Illness and Mental Health: The Two Continua Model across the Lifespan. Journal of Adult Development, 17, 110-119. http://dx.doi.org/10.1007/s10804-009-9082-y

WHO (2011). Use of Glycated Haemoglobin (HbA1c) in the Diagnosis of Diabetes Mellitus: Abbreviated Report of a WHO Consultation. WHO Reference Number: WHO/NMH/CHP/CPM/11.1

http://apps.who.int/iris/bitstream/10665/70523/1/WHO_NMH_CHP_CPM_11.1_eng.pdf 